TEACHING AND LEARNING ETHICS

\title{
Subtracting insult from injury: addressing cultural expectations in the disclosure of medical error
}

\author{
N Berlinger, A W Wu
}

See end of article for

authors' affiliations

J Med Ethics 2005;31:106-108. doi: 10.1136/jme.2003.005538

Correspondence to:

$N$ Berlinger, The Hastings

Center, 21 Malcolm

Gordon Road, Garrison,

New York 10524, USA;

berlingern@

thehastingscenter.org

Received 25 June 2003

In revised form

22 October 2003

Accepted for publication

24 October 2003
This article proposes that knowledge of cultural expectations concerning ethical responses to unintentional harm can help students and physicians better to understand patients' distress when physicians fail to disclose, apologise for, and make amends for harmful medical errors. While not universal, the JudeoChristian traditions of confession, repentance, and forgiveness inform the cultural expectations of many individuals within secular western societies. Physicians' professional obligations concerning truth telling reflect these expectations and are inclusive of the disclosure of medical error, while physicians may express a need for self-forgiveness after making errors and should be aware that patients may also rely upon forgiveness as a means of dealing with harm. The article recommends that learning how to disclose errors, apologise to injured patients, ensure that these patients' needs are met, and confront the emotional dimensions of one's own mistakes should be part of medical education and reinforced by the conduct of senior physicians.
$\mathrm{P}$ hysicians are inclined to be honest with their patients, but telling the truth and taking responsibility for one's mistakes may challenge a physician's commitment to honesty. If physicians believe "disclosure means exposure", their instinct for self-preservation may prevail over their desire and professional obligation to tell the truth. ${ }^{1}$ When these two contradictory impulses-to disclose mistakes and to conceal them-come into play in incidents of medical error, it is disturbing to patients and physicians alike.

Understanding cultural expectations concerning responses to harmful error can provide physicians with insight into injured patients' needs. In this article, we discuss two of these expectations: truth telling and forgiveness. Our reflections are supplemented by observations from clinicians and educators, in the literature and through informal conversations.

\section{RELIGIOUS VALUES IN SECULAR SOCIETIES}

Whether or not we consider ourselves to be personally religious, secular western societies continue to be influenced by Judeo-Christian norms concerning social ethics. For example, "forgiveness" has become an important area of theoretical enquiry and empirical research for social scientists, legal scholars, and ethicists seeking to draw upon recognised cultural norms, often but not exclusively derived from religion, to effect reconciliation in the political sphere. ${ }^{23}$ Other legal scholars, whose research focuses on health law and tort reform, are also looking at apology and forgiveness, among other concepts whose language and practices may be derived from or associated with Judeo-Christian religious and cultural traditions. ${ }^{4}$

Learning more about how these influential traditions handle human fallibility can help physicians to understand why patients and families affected by adverse incidents expect an explanation, an apology, and assurance that such incidents will not happen again. ${ }^{5}$ As the examples suggest, these traditions also highlight the cultural importance of forgiveness as a strategy for dealing with harm. When a physician refuses to tell an injured patient what really happened, the patient may literally not be able to forgive this physician, and may not be able to detach and move on from a distressing event.

In the Old Testament, the most frequently used word for "error" is het, meaning "to miss the mark". ${ }^{67}$ When one misses the mark in terms of another person, Jewish and Christian traditions prescribe a series of concrete, reciprocal practices: confession, which includes disclosure and apology; repentance, which includes the actions that the person who has harmed another undertakes to compensate for the error; and forgiveness, through which the person who has been harmed signals that he or she has been adequately compensated. ${ }^{5}$ These practices may serve as a lifelong reference point for ethical conduct. For example, the Lord's Prayer is a touchstone for many Christians with respect to ethical behaviour concerning error and forgiveness. It is based on Matthew 6:9-13, ${ }^{8}$ and should be compared with Luke 11:2-4. ${ }^{9}$ This prayer includes a ritualised confession"forgive us our trespasses, as we forgive those who trespass against us" - in which the Greek word opheilaymata, often rendered in English as "trespasses", literally means "debts", suggesting that something is owed when we make a mistake. Even without knowing Greek, we know that to "trespass" means to violate a boundary. When we trespass by making a mistake, we need to acknowledge we have crossed a line and may have caused damage to the property-the body, the life-of another person.

\section{FORGIVENESS AND "CHEAP GRACE"}

While clinical research suggests the ability to forgive is a mark of psychological health, ${ }^{10}{ }^{11}$ a coercive approach to forgiveness ignores its responsive character and makes the harmed party responsible for making things right. To expect forgiveness without first disclosing, apologising for, and making amends for one's mistakes is to expect what Christian theologian Dietrich Bonhoeffer disparagingly calls "cheap grace". ${ }^{12}$ As a theological concept, grace describes the relationship between a person and the loving God who forgives the errors this person will inevitably make. As an ethical concept, grace describes human relationships in which dignity is honoured and life affirmed or improved 
through concrete acts. ${ }^{13}$ Cheap grace is the devaluing of these relationships.

\section{SELF-FORGIVENESS}

The issue of "self-forgiveness" may arise when physicians talk about their own errors. One physician, defining what members of his profession mean by self-forgiveness as "freedom from guilt and self-hatred", questions this appropriation of traditional language: "there must be a self-transcending aspect to forgiveness - or it does not occur." ${ }^{14}$ This physician has recognised that self-forgiveness can be cheap grace if it excludes consideration of the patient. However, if by self-forgiveness physicians really mean "freedom from guilt and self-hatred" after the existential blow of harming a patient, then it can be construed as a process separate from, related to, and ideally following from the ethical process of forgiveness. Helping to heal the wound in the physician-patient relationship by fulfilling a patient's cultural expectations may therefore help physicians to "forgive" themselves by helping them to recover their identities as healers.

\section{CONFESSION}

Bonhoeffer argues that the most effective way to grasp one's ethical responsibilities in a given situation is to see it "from the perspective of those who suffer". ${ }^{15}$ This perspective can be useful to a physician who is grappling with the practical questions of what to say and do after medical mistakes. Recognising that this perspective belongs to the injured patient, and that one's own feelings cannot be conflated with or substituted for those of the patient, may help physicians to keep the patient's needs uppermost, while addressing their own needs in an appropriate manner. Disclosure and apology, the "confession" that begins the process culminating in forgiveness, together constitute the first step towards meeting the patient's needs and expectations. The importance of disclosure has been recognised for more than a decade in the USA by the American Medical Association ${ }^{16}$ and the American College of Physicians, ${ }^{17}$ and more recently by the Joint Commission on Accreditation of Healthcare Organizations, whose ethical standards now require hospitals to inform patients about errors and other "unanticipated outcomes" ${ }^{\prime 18}$ In the UK, the General Medical Council recognises disclosure and apology as professional obligations. ${ }^{19}$

That said, telling the truth about error is not easy, in part because clinicians involved in medical mistakes may never be given the opportunity to apologise to an injured patient, and may even have been instructed not to communicate with such patients or their families. Current models of disclosure may not require physicians to disclose and apologise personally for their own mistakes. ${ }^{120}$ We and others have argued that physicians should take responsibility for their own errors by personally disclosing and apologising for them, and that they need training in how to do so. Disclosing an error to a patient or family can be viewed as an instance of breaking bad news, and keeping patients informed about adverse incidents should be a natural feature of the patient-physician dialogue. ${ }^{21-23}$

Two cases may help to illustrate how disclosure works within the context of this dialogue. In the first case, a physician prescribes an antibiotic for a patient despite the fact that the patient has a known allergy to this medication, and that this information is printed on the front of the patient's medical record. The patient takes the prescribed antibiotic, develops a severe rash, and returns to see the physician. In this case, it would be appropriate for the physician to point out to the patient that the rash was most likely caused by the medication, to acknowledge that he made an error in prescribing this medication, to apologise for the resulting harm to the patient, and to describe steps to be taken to mitigate the ill effects of the medication. These actions would permit the patient to forgive the physician, saying something to the effect of: "That's okay, doctors are human too. I forgive you." Notice that the physician does not explicitly ask for the patient's forgiveness, but rather gives the patient the opportunity to respond to his disclosure as the patient sees fit.

In the second case, a physician is concerned about a change in the health status of a hospitalised patient and orders a blood test. The blood is drawn and sent to the lab. The test reveals profound anaemia. However, owing to short staffing, the results are not telephoned to the physician. The physician does not check the results herself until several hours later. By that time the patient, who had unsuspected bleeding, had lost more blood and suffered a heart attack. In this case, the physician would, in disclosing the error to the patient, apologise both on her own behalf and on behalf of the institution, as responsibility for this error is shared between the system and the individuals working within it. Such systems errors are believed to comprise the large majority of medical mistakes.

While a systems approach to addressing error requires understanding all of the factors that contribute to it, it does not absolve individuals from responsibility. In Sweden and Denmark "no-fault" compensation is available to persons sustaining avoidable iatrogenic injuries that have a lasting impact. ${ }^{24-26}$ These programmes, which have also been proposed in other countries, are made feasible by strong social welfare systems, which include universal health care coverage and disability insurance. Yet the Swedish and Danish no-fault compensation funds cannot function if individual health care workers do not take responsibility for their mistakes by disclosing them. Advocates of no-fault compensation would therefore do well to underscore the relationship between this "system" reform and individual responsibility, and be mindful of the need to eliminate the potentially negative repercussions of disclosure if no-fault is to prove a viable option in other western nations.

Responsibility should not be confused with blame, although that is too often the sense in which it is used in discussions of medical error and in particular of medical malpractice. Rather, the individual who takes responsibility within a systems approach will be committed to "prospective responsibility": discussing and analysing mistakes, improving practices, and fulfilling his or her role obligations, including the duty to disclose. ${ }^{27}$ The physician-patient relationship exists between individuals, not between a person and a "system", and telling injured patients the truth involves honest conversations between patients and the caregivers they know and trust.

Learning how to disclose errors, apologise to injured patients, and ensure that these patients' needs are met, while honestly confronting the impact of error upon oneself, should be part of medical education. These skills should be reinforced and modelled by the example of senior physicians. Medical educators should address the corrosive effect that withholding the truth from injured patients may have upon the professional ethics of health care providers. They should also frankly discuss the inequitable distribution of power between physicians and patients, and between physicians and subordinates, as it pertains to medical error. For example, a physician has the power to describe a patient as "noncompliant" or a medical failure as a "complication", and these descriptions can potentially be used to conceal or avoid confronting mistakes.

\section{REPENTANCE}

Simply "telling the truth", and even apologising, are unlikely in themselves to fulfil a patient's expectations. 
Demonstrating to the injured patient and the family that their experience has been treated seriously, and that measures have been taken to prevent a recurrence, constitute the next step of the process. Other actions that physicians and hospitals can take include: providing fair compensation for injuries, with the burden of compensation shared among responsible parties; ${ }^{28}$ offering patients and families access to counselling services; and inviting them to contribute to the hospital's quality improvement process by sharing their experience. Findings from one US study suggest that providing fair compensation prevents malpractice suits not only because patients receive adequate financial settlements, but also because maintaining a caregiving relationship with patients and families "diminishes the anger and desire for revenge that often motivates patients' litigation". ${ }^{19}$

Honouring the patient's perspective also means accepting the difficult reality that some patients will not want any contact with those responsible for their injuries. Physicians should not expect to hear any patient say "I forgive you" as a quid pro quo for disclosure, apology, and repentance. The goal is to make it possible for patients to forgive, not to obligate them to do so. Physicians and staff involved in disclosing an error must be careful not to take advantage of any patient's religious or cultural orientation towards forgiveness. Western religious and cultural norms, while influential, are not universal. A growing literature on cultural autonomy and medical decision making attests to differing norms with respect to breaking bad news and other aspects of physician-patient communication. ${ }^{29}{ }^{30}$ Informal discussions with professionals familiar with Hinduism and Buddhism reveal different metaphors-for example, "compassion" rather than "forgiveness" - and different ways of describing what is expected after one person harms another. More attention is needed to non-western paradigms of ethical behaviour after an error has occurred so that physicians can be attuned to differing cultural expectations among their patients. This is emphatically not to say that physicians should appropriate the perceived or assumed cultural norms of their patients. Rather, it is to say that they should, at minimum, be aware that, just as a patient's "explanatory model" of a health problem is to some extent culturally derived, so a patient's expectations of what ought to be said and done after a mistake that is harmful to that patient's health may also be shaped by religiocultural norms concerning appropriate means of dealing with unintentional harm. ${ }^{31}$ The same point may, of course, be made about physicians' own expectations, which are shaped by the cultural norms of medicine. As Arthor Kleinman asks in remarks cited by Anne Fadiman: "If you can't see that your own culture has its own set of interests, emotions, and biases, how can you expect to deal successfully with someone else's culture?'32

\section{CONCLUSION}

David Hilfiker writes that if health care providers "cannotto some extent-see the world from the victim's point of view, they'll have a difficult time developing an ethical framework in which to work." ${ }^{\prime 33}$ Seeing medical errors from the perspective of patients' cultural expectations may make it easier for the medical profession to handle errors in ways that meet patients' needs. Paying attention to cultural expectations surrounding error and forgiveness may also help the physician who has disclosed, apologised, and made amends for a mistake to meet his or her own needs.

\section{Authors' affiliations \\ N Berlinger, The Hastings Center, Garrison, New York, USA}

A W Wu, Department of Health Policy and Management, School of Public Health, The Johns Hopkins University, Baltimore, MD, USA

Dr Berlinger's work was funded by a grant from the Patrick and Catherine Weldon Donaghue Medical Research Foundation. Dr Wu's work was funded by the US Department of Health and Human Services Agency for Healthcare Research and Quality, grant number U18HS11902-01.

\section{REFERENCES}

1 Hamm G, Kraman SS. New standards, new dilemmas-reflections on managing medical mistakes. Bioethics Forum 2001;17:19-25.

2 Shriver DW. An ethic for enemies: forgiveness in politics. New York: Oxford University Press, 1995

3 Minow M. Between vengeance and forgiveness: facing history after genocide and mass violence. Boston, MA: Beacon Press, 1998.

4 Cohen JR. Advising clients to apologize. Southern California Law Review 1999;72:1009-69.

5 Gallagher TH, Waterman AD, Ebers AG, et al. Patients' and physicians' attitudes regarding the disclosure of medical errors. JAMA 2003;289:1001-7.

6 Werblowsky RJZ, Wigoder G, eds. Oxford dictionary of the Jewish religion. New York: Oxford University Press, 1997:646.

7 Freedman DN, ed. Anchor Bible dictionary, vol. 6. New York: Doubleday, 1992:32.

8 Matthew 6:9-13. The Holy Bible.

9 Luke 11:2-4. The Holy Bible.

10 Freedman SR, Enright RD. Forgiveness as an intervention goal with incest survivors. J Consult Clin Psychol 1996;64:983-92.

11 Kaminer D, Stein DJ, Mbanga I, et al. The Truth and Reconciliation Commission in South Africa: relation to psychiatric status and forgiveness among survivors of human rights abuses. $\mathrm{Br} J$ Psychiatry $2001 ; 178: 373-7$.

12 Bonhoeffer D. Discipleship. (First published as Nachfolge in German in 1937.) In: Kelly G, Godsey J, eds. Green B, Krauss R, trans. Works, vol. 4. Minneapolis, MN: Fortress Press, 2001:43.

13 Russell LM, Clarkson JS, eds. Dictionary of feminist theologies. Louisville, KY: Westminster John Knox Press, 1996:134.

14 Berlinger N. Avoiding cheap grace: medical harm, patient safety, and the culture(s) of forgiveness. Hastings Cent Rep 2003;33(6):28-36.

15 Bonhoeffer D. After ten years. (First published 1951.) In: Bethge E, ed. Fuller R, Clark F, Bowden J, trans. Letters and papers from prison. New York: Simon \& Schuster, 1997:17.

16 American Medical Association. Code of medical ethics; ethical opinions, E8.12. March 1981; updated June 1994. http://www.ama.assn.org/ama/ pub/category/8497.html (accessed 30 Jan 2002).

17 American College of Physicians. Ethics manual; disclosure. March 1998. http://www.acponline.org/ethics/ethicsman.htm /accessed 12 Sept 2002).

18 Joint Commission on Accreditation of Healthcare Organizations. Revisions to Joint Commission standards in support of patient safety and medical/health care error reduction. Oakbrook Terrace, IL: JCAHO, 2001:RI.1.2.2.

19 General Medical Council. Good medical practice; item 22, p 8. http:// www.gmc-uk.org/standards/good.htm (accessed 31 Mar 2003).

20 Kraman SS, Hamm G. Risk management: extreme honesty may be the best policy. Ann Intern Med 1999;131:963-7.

21 Wu AW. Handling hospital errors: is disclosure the best defense? Ann Intern Med 1999;131:970-2.

22 Wu AW, Cavanaugh TA, McPhee SJ, et al. To tell the truth: ethical and practical issues in disclosing medical mistakes to patients. J Gen Intern Med $1999 ; 12: 770-5$.

23 Berman S. Reporting outcomes and other issues in patient safety: an interview with Albert Wu. Journal of Quality Improvement 2002;28:197-204.

24 Erichsen M. The Danish patient insurance system. Med Law 2001 ;20:355-69.

25 Studdert DM, Brennan TA. No-fault compensation for medical injuries: the prospect for error prevention. JAMA 2001;286:217-23.

26 Shapiro D. Beyond the blame: a no-fault approach to malpractice. New York Times (online edition) 2003 Sept 23;Sect F: 6. http://www.nytimes.com (accessed 23 Sept 2003).

27 Sharpe VA. Promoting patient safety: an ethical basis for policy deliberation. Hastings Cent Rep 2003;33(5):S1-20.

28 Bayley C. Turning the Titanic: changing the way we handle mistakes. HealthCare Ethics Committee Forum 2001;13:148-59.

29 Moazam F. Families, patients, and physicians in medical decisionmaking: a Pakistani perspective. Hastings Cent Rep 2000;30(6):28-37

30 Hyun I. Waiver of informed consent, cultural sensitivity, and the problem of unjust families and traditions. Hastings Cent Rep 2002;32(5):14-22.

31 Kleinman A. Writing at the margins: discourse between anthropology and medicine. Berkeley, CA: University of California Press, 1995:8-9.

32 Fadiman A. The spirit catches you and you fall down: a Hmong child, her American doctors, and the collision of two cultures. New York: Farrar, Straus and Giroux/The Noonday Press, 1997:261.

33 Hilfiker D. From the victim's point of view. Journal of Medical Humanities $2001 ; 22: 255-63$ 